\title{
El liberalismo en América Latina
}

Deni Trejo Barajas

\footnotetext{
E
} 1 interés fundamental de este trabajo es exponer, de manera general, las características que asume el liberalismo en América Latina: desde su surgimiento con las ideas ilustradas a fines del siglo XVIII hasta su desarrollo, complejo y contradictorio, éste debido al proceso de secularización de la sociedad, modernización del Estado y generalización de sus principales ideas y principios.

Entiendo al liberalismo como la expresión ideológica y política de la génesis y afirmación de la sociedad capitalista occidental, surgida ésta de un largo proceso iniciado en Europa hacia el siglo xIV con la llamada acumulación originaria, con la ruptura de la sociedad feudal y con la afirmación y posterior caída del Estado monárquico absoluto; con la escisión de la Iglesia católica romana, la cual dio lugar al surgimiento del protestantismo; con la revolución industrial inglesa en el siglo xviII; con el desarrollo intelectual del llamado movimiento ilustrado; con las revoluciones francesa y norteamericana que lograron despojar a lá antigua aristocracia mediante movimientos revolucionarios, a la vez que hacían acceder a la burguesía al poder del Estado.

El siglo xIX marca la cúspide del capitalismo de libre competencia, y es también la etapa del surgimiento y elaboración de alternativas a la dominación burguesa, me refiero, por ejemplo, a planteamientos elaborados por socialistas y anarquistas y a la presencia fundamental de movimientos populares con reivindicaciones propias.

Si la historia del liberalismo europeo está íntimamente emparentada con la del sistema capitalista, la del liberalismo latinoamericano no puede quedar al margen de este proceso aunque con formas y caracteres específicos dada la situación colonial de nuestros pueblos.

Las tareas y objetivos liberales en América Latina se inauguran prácticamente con las luchas de independencia; sin embargo, nuestro liberalismo tiene antecedentes importantes en la política reformista del absolutismo borbónico y en la ilustración americana de fines del siglo Xvili, dado que los planteamientos desarrollados en Europa tienden a extenderse a otras áreas junto con el sistema capitalista mismo, aunque en permanente conflicto con la situción colonial. Así por ejemplo, en América Latina, en el plano económico, el objetivo liberal es la libertad de comercio en una región dominada por monopolios; en el plano político, el objetivo es el constitucionalismo y la democracia en una región donde el poder absoluto del monarca y de sus representantes en América no puede cuestionarse; en el plano social, el objetivo es la secularización y la modernización de una sociedad en donde predo-

* Este artículo es una síntesis del trabajo realizado para una conferencia en la Universidad de Zacatecas. 
mina la Iglesia sobre las diversas actividades comunes de la vida y en donde, generalmente, el gran terrateniente establece relaciones serviles o hasta de esclavitud con la fuerza de trabajo rural.

La crisis del antiguo régimen implicó la desestructuración del sistema mercantilista colonial y la transformación del sistema capitalista europeo en mundial. La inoperante política monopolista de la península ibérica encontraba un límite en el avance capitalista europeo y en las crisis internas de las economías coloniales.

En este contexto podemos insertar y comprender los cambios generados en el interior de la política española y portuguesa en sus respectivos periodos reformistas. Podemos decir que es a través de la propia política metropolitana que comienzan a introducirse algunos planteamientos de corte liberal ante la necesidad apremiante de las viejas metrópolis de reubicarse en el contexto de la transformación del sistema capitalista europeo.

$\mathrm{Su}$ objetivo era recobrar el poder económico y político en sus colonias a través de reformas que implicaban un intento de modernización del aparato estatal cuya labor era la eliminación de corporaciones y monopolios (excepto el de la Corona); la racionalización de la actividad fiscal y administrativa; la liberación paulatina del comercio; la renovación de la enseñanza, etcétera.

El liberalismo introducido con la política reformista española estaba más relacionado con la necesidad económica de recobrar el poder perdido en este terreno ante el avance inglés que con la idea política de democratizar la sociedad. Y en este punto el reformismo significó más bien una mayor estrechez en las posibilidades de acceso al poder político por parte de los criollos, a la vez que un ataque a varios sectores económicos dominantes como los comerciantes monopolistas, la Iglesia y los hacendados.

Jovellanos fue, justamente, la figura más representativa de la ilustración española, pero su pensamiento, como el de Campomanes, Cabarrús y tantos otros, se orientó hacia los problemas de la economía y de la educación. Las ideas de la escuela liberal y especialmente de la fisiocracia inspiraron las medidas económicas de los gobiernos ilustrados. ${ }^{1}$

En el plano político el liberalismo borbónico no podía cuestionar a la monarquía absoluta y, si bien en la península tendía a desplazar a la aristocracia y a utilizar a sectores medios en el proceso de modernización del Estado, en las colonias, el proceso tendía a una exacerbación del autoritarismo burocrático y económico y a la eliminación de las posibilidades de acceso al poder de los grupos criollos.

Liberalismo en el plano económico, conservadurismo en el políticosocial serán algunos de los aspectos que heredaran nuestras jóvenes repúblicas de la política borbónica.

Es interesante anotar también cómo los ilustrados americanos, insertos en el mundo colonial pero formados en las expectativas propuestas por la renovación intelectual europea, viven esa contradicción entre tradición y modernidad. Empapados ya de las tendencias racionalistas de la época, del interés por entender la naturaleza a partir de la observación y la experiencia, los jesuitas y otros intelectuales comenzaron a trocar el interés por la naturaleza divina en interés por la naturaleza

${ }^{1}$ Jose Luis Romero, Situaciones e ideologias en América Latina, México, Unam, p. 56. 
humana. El naturalismo, el individualismo, el racionalismo comenzaron a ser invocados aunque sin cuestionar a fondo las bases de la filosofia escolástica.

Este periodo lo podemos conocer mejor a través de lo que se conoce como el "periodismo ilustrado", del cual hay notables ejemplos en América Latina, aunque por ahora sólo expondré algunas particularidades del periodismo peruano a finales del siglo xvin a través de una publicación salida a la luz hacia 1791 y llamada Mercurio Peruano.

Participaban en este periódico notables intelectuales de la época que habían sido desplazados de la Universidad de San Marcos de Lima por sus ideas renovadoras frente a la Iglesia.

La ideología del Mercurio Peruano va a estar determinada por varios factores:

1) La presencia todavía dominante de la filosofía escolástica y de ciertas tradiciones y prejuicios religiosos.

2) El desarrollo limitado de cierta apertura ideológica en España y América dirigida por la misma monarquía.

3) El desarrollo en Europa, bajo el impulso y ascenso capitalista, de nuevas concepciones que tienden a romper con las antiguas formas de pensar y vivir.

4) Las características mismas de la realidad americana (geográficas e histórico-culturales).

Sin lugar a dudas podemos decir que hay un interés fundamental por el hombre en los mercuristas. Nuevos valores que empiezan a controvertirse con los tradicionales se manejan en El Mercurio de una manera natural y como ideales a lograr, tales como la laboriosidad, el espíritu de arrojo, la ilustración, el ingenio, la sobriedad; los defectos están referidos a la ociosidad, la ignorancia y el despilfarro. Son los valores de la ética del buen burgués los que comienzan a tener presencia frente a aquella visión tradicional que tenía al aristócrata rodeado de lujos y privilegios como el tipo social por excelencia.

Uno de los aspectos fundamentales de El Mercurio son sus ideas económicas, a través de las cuales expresa que la situación económica y social en el Perú es algo determinado por la naturaleza y que no es posible cambiar, pero sí aprovechar. Para ellos, la naturaleza dota a las distintas regiones a su antojo" de tal manera que el Perú resultar ser un país fundamentalmente minero y no agrícola, desprendiéndose de esto una política que tiende a fomentar únicamente la minería y a despreciar la agricultura.

Siguiendo principalmente los planteamientos fisiocráticos, creen en la existencia de un orden natural al que hay que respetar; esto les permite amalgamar los intereses económicos del grupo dominante criollo, que ve en la minería la única alternativa para salir de la crisis, con una visión social jerárquica que les permite en los sectores altos, en el mismo nivel que los españoles, a la vez que justificar la existencia de la pobreza del indio y del negro como algo preestablecido y fuera de su poder. Su respuesta a las diferencias sociales la encontrarán en la caridad cristiana.

A través de ambos polos ideológicos, humanismo ilustrado y caridad cristiana, se unían de manera coherente en la elaboración ideológica de los americanos la existencia de la desigualdad social, su justificación y el interés por lograr la armonía social, sin modificar la estructura existente.

Los mercuristas elaboraron así un complejo ideológico de acuerdo 
con sus intereses y con sus aspiraciones de convertirse en representantes de un tipo de hombre nuevo que en el Perú era prácticamente inexistente como clase social pero que se mostraba como el ideal a seguir.

Todos estos elementos que hemos mencionado rápidamente hasta ahora, tenían que ver con el proceso de transición del feudalismo al capitalismo naciente, pero con la característica fundamental de situarse en una colonia que en ese momento sufría un proceso de debilitamiento. El reformismo borbónico había abierto la posibilidad de adecuar al Perú a los nuevos requerimientos metropolitanos y mundiales. Ahí El Mercurio peruano cumplió una enorme labor con el objeto de no dejar caer a la región en un papel marginal dentro de la economía mundial (aunque a futuro esto significaría la continuación de la dependencia). En esta lucha, el periódico lograría algo que no se había propuesto de principio: el deterioro de los valores en que se sustentaba el poder monárquico y la dependencia de España.

El periodo de lucha por la independencia marca un hito en el proceso de conformación del liberalismo latinoamericano.

Ubicadas las revoluciones de independencia en el contexto de las revoluciones burguesas tenían que asumir muchas de las espectativas de éstas aunque sin haber desarrollado los elementos estructurales para poder instaurar un régimen burgués.

El carácter de colonia había imposibilitado la formación de clases susceptibles de impulsar coherentemente un proyecto revolucionario burgués.

La ruptura del dominio ibérico planteaba entonces la posibilidad de cambiar los términos del poder ejercicio hasta entonces por los españoles: el problema estaba en que la herencia colonial de nuestros pueblos hacia permanecer las relaciones de producción coloniales por la presencia dominante de un sector que saldrá fortalecido después de las luchas de independencia, el de los terratenientes. Este sector basaba su poder en la sujeción económica y extraeccnómica del campesino, así como en el dominio sobre economías regionales dispersas en un vasto territorio que ni el poder peninsular había logrado cubrir a cabalidad.

La tarea fundamental que el liberalismo occidental ponía a la orden del día en América Latina, el de la construcción del Estado nacional, tenía numerosos problemas que enfrentar. En primer lugar, el hecho de que varios sectores participantes en la lucha por la independencia no se la plantearan como una "lucha antifeudal" sino únicamente como el medio de acceder al poder político y económico.

Según Florestán Fernández, el liberalismo, en la lucha por la independencia, brinda las armas para enfrentarse al absolutismo monárquico y se plantea como la opción más clara hacia la configuración del Estado nacional burgués; sin embargo, ese mismo liberalismo entrará en contradicción absoluta con los intereses sociales tradicionales y dominantes en América, por lo que el camino que seguirá el desarrollo de los nuevos países será de lo más tortuoso y conflictivo.

En este sentido, podemos afirmar que las élites nativas no se levantaron contra la estructura de la sociedad colonial, de carácter tradicional y precapiralista, sino contra las implicaciones económicas, sociales y políticas del estatuto colonial que limitaba su capacidad de dominación en todos los niveles del orden social y político. Basta recordar el papel que desempeñaban las corporaciones y monopolios para comprender la rebeldía de dichas élites americanas. 
Desde esa perspectiva, la independencia presuponía, simultáneamente, un elemento puramente revolucionario y otro elemento específicamente conservador. El elemento revolucionario aparecía en los propósitos de despojar al orden social, heredado de la sociedad colonial, de los caracteres heteronómicos en los cuales fuera moldeado, requisito para que adquiriese la elasticidad y la autonomía exigidas por una sociedad nacional. El elemento conservador se evidenciaba en los propósitos de preservar y fortalecer, a toda costa, un orden social que no poseía condiciones materiales y morales suficientes para engendrar el modelo de autonomia necesario para la construcción y el florecimiento de una nación. ${ }^{2}$

Las diversas actividades económicas, en especial la agricultura y la mineria, en las condiciones en que podían ser explotadas productivamente, o aún más, en aquellas situaciones en que no era así, imponían la perpetuidad de las estructuras del mundo colonial, de la servidumbre, de la esclavitud, de la extrema concentración de la renta y el monopolio del poder por reducidas élites. Con ello hacían prevalecer una estructura social en evidente contradicción con los supuestos teóricos del liberalismo.

Con todo, el elemento revolucionario en la independencia (empapado ideológicamente del liberalismo) era el componente verdaderamente dinámico y propulsor. Por eso, aunque reinterpretado y deformado en algunos de sus aspectos, se convirtió en el fermento histórico del comportamiento social a corto plazo, además de alimentar y orientar las opciones que delimitaron, en los planos ideológicos y utópicos, los ideales de organización del Estado nacional.

El liberalismo suministró las concepciones generales y la filosofía política que dieron sustancia a los procesos de modernización derivados primero, de la extinción del estatuto colonial y después, de la disgregación, lenta y heterogénea pero progresiva, del propio orden colonial. No afectó, en principio, los aspectos de la vida social, económica y política que continuaron gravitando en torno a la servidumbre, la esclavitud y las formas tradicionales de dominación patrimonialistas. Aunque no podemos dejar de mencionar que hubo intentos importantes para modificar estos aspectos con medidas abolicionistas o reformistas, como en el caso de los movimientos dirigidos por Hidalgo, Morelos, Artigas, Bolívar u O'Higging.

El liberalismo contribuyó a revolucionar el horizonte cultural de las élites nativas, primero, proporcionándoles categorías de pensamiento y de acción que condujeron a concientizarlas sobre el despojo colonial del que eran objeto y la oposición al sistema colonial mercantilista; segundo, preparándolas intelectualmente para la defensa de la independencia de la república o de la monarquía constitucional (en el caso brasileño) y de la nueva organización del poder político centrada en el acceso al aparato del Estado de dichas élites; y tercero, poniendo en entredicho, en algunos casos, las bases de los sistemas productivos tradicionales.

Por otro lado, el liberalismo mostraba una doble cara: mientras que representaba la vía por la cual se restablecían, en condiciones diferentes, los nexos de dependencia, revelaba a la vez el camino de la autonomía y de la supremacía de algunos grupos minoritarios, que lograrían

${ }^{2}$ Florestán Fernández, La revolución burguesa en Brasil, México, Siglo XXI, 1978. p. 40 . 
privilegiar su status social y apoderarse del control del destino de la colectividad.

En el proceso de la revolución de independencia se generaron movimientos diversos, cargados también de diversa manera de elementos ideológicos liberales, esto en función de los específicos intereses que representaban.

En un primer momento, la revolución en las colonias hispanoamericanas reprodujo en términos generales los argumentos enunciados por la burguesía europea.

Considerando la caida del monarca ante el avance de las tropas napoleónicas se expresaba en el lenguaje del contractualismo naturalista: América - decían - era súbdita del Rey, y no de España; y estando el monarca preso, se imponía una redefinición del orden jurídico; los pueblos recobraban sus derechos. ${ }^{3}$

Es el periodo de la organización de las juntas representativas de Fernando VII. El poder político de la Corona entraba en una fase crítica: las "fuerzas vivas" asumían la posibilidad de gobernarse sin el monarca.

Un segundo momento comprenderá la polémica acerca de la forma de gobierno. Es la etapa de la definición de la lucha por la independencia y de la opción que debía escogerse en cuanto a la organización política.

Francisco de Miranda, por ejemplo, ausente de Venezuela desde 1771 y participante en el proceso revolucionario francés, tenía la opinión de que el imperio colonial español era ya en mucho anacrónico, y en su concepción de la independencia estaba implícita la de su renovación para que se modernizara y ocupara un lugar provechoso en el mundo mercantil.

Su concepción de lo que debía ser Hispanoamérica después de la independencia estaba influida por el por modelo político inglés. Cuando participó en el Congreso que redactó la Constitución Venezolana de 1811 , asistió con desagrado a la adopción de un conjunto de principios e instituciones que, en su opinión, comprometian el futuro del país. El régimen político pero, sobre todo, el principio federalista, contradecían sus convicciones.

Otras formas de expresión de tendencias más radicales fueron las desarrolladas en algunas ciudades por la pequeña burguesía y capas medias urbanas, ejemplo de ello son las posturas de Mariano Moreno o Bernardo Monteagudo a quienes se conocía por sus tendencias afrancesadas, ya que eran lectores asiduos de los filósofos franceses. El mismo Mariano Moreno haría una traducción del contrato social de Rousseau, claro que su radicalismo encontraba límites en algunos aspectos como el religioso. Así tenemos que en el prólogo a dicha traducción Moreno decía:

como el autor tuvo la desgracia de delirar en materia religiosa, suprimo el capítulo y principales pasajes donde ha tratado de ellas. ${ }^{4}$

A pesar de estas limitaciones, las ideas fundamentales de Rousseau, aparecieron una y otra vez en los escritos de los revolucionarios y más

${ }^{3}$ Pedro Cuperman.

${ }^{4}$ José Luis Romero, op. cit., p. 61. 
allá de las consignas estrictamente autonomistas, el ideal republicano empezó a manifestarse como la mejor opción. Socialmente, las expectativas igualitarias y democráticas comenzaron a manejarse y se habló entonces de la supresión de privilegios y de eliminar la esclavitud y la servidumbre indigena.

Hidalgo, Morelos, Artigas, Monteagudo, Rodríguez de Quiroga, Zudañez y otros participantes directos en los movimientos revolucionarios de México, Río de la Plata y el Alto Perú, expresaron una y otra vez una versión más o menos radical de aquellas ideas.

Monteagudo en particular, conmoverá el panorama político e ideológico rioplatense con sus escritos muchísimo más avanzados e incendiarios que los de Moreno. Con Monteagudo se produce la ruptura con la tradición hispana que en la revolución se había manifestado como fidelista o como separatista moderada y evolutiva.

Monteagudo formula críticas al antiguo régimen, a la obra de España en América, a sus gobernantes. Idealiza también al indígena americano, a su cultura, a sus gobernantes, para oponerlo al conquistador pirata y sanguinario que destruyó el antiguo paraíso terrenal. Su "diálogo entre Atahualpa y Fernando VII" es expresión clara de esta postura.

La prédica independentista de Monteagudo, iniciada en 1811, encontraría al principio una general oposición pero, con el tiempo, su posición independentista radical se extendería, aunque él en lo personal, comenzaba un proceso en sentido inverso, es decir, hacia el conservadurismo (Me refiero a la época en que, junto con el caudillo San Martín en el Perú, trataría de impulsar un proyecto político monárquico).

Un caso que merece ser mencionado especialmente es el de José Artigas, revolucionario de la Banda Oriental del Río de la Plata (Uruguay), cuyo pensamiento jurídico, político e ideológico tiene un carácter radical.

Según algunos autores, el pensamiento de Artigas sufre influencias de Paine, de Mac'Culloch y de la propia Constitución Americana que lo llevaron a elaborar una doctrina basada en el respeto a la soberanía popular, a pregonar la necesidad de romper con la península, a declararse por la independencia absoluta y por el federalismo.

Coincidimos con Ricaurte Soler en identificar como demócratas y, más específicamente, como demócratas radicales, a aquellos procesos de raíz popular que, a partir de la independencia, se empeñaron en conjugar las tareas de la organización nacional con las reivindicaciones sociales de las clases subordinadas. Dentro de esta tendencia podríamos considerar los movimientos que surgen de reivindicaciones agrarias y de corte popular. Este es el caso de Hidalgo y Morelos en América del Norte y el ya mencionado de Artigas en América del Sur. Para ellos, junto con las tareas igualitarias y de eliminación de privilegios está la muy importante de redistribución de tierra. Así, Artigas, en su Reglamento para el fomento de la campaña y seguridad de sus hacendados, dice que "los terrenos repartibles son todos aquellos de emigrados, malos europeos y peores americanos", igualmente se refiere a "todas aquellas tierras vendidas o donadas por los realistas entre 1810 y $1815 \ldots$..", es decir, que la mayor parte de las tierras de la Banda Oriental quedaban sujetas a la categoría de "tierras repartibles".

Con la realización de estas tareas se intentaba organizar el gobierno de los americanos. La eliminación de la esclavitud, de las distinciones 
de casta, de tributos, de trabajo gratuito indígena y el intento de universalización de la pequeña y mediana propiedad agraria son sus elementos fundamentales.

Sin embargo, este tipo de proyectos encuentra inmediatamente enormes contradicciones. El escaso desarrollo de las fuerzas productivas es la razón de fondo que explica, en términos generales, el fracaso de la organización nacional propuesta por el radicalismo agrario.

La derrota de los movimientos independentistas sustentados sobre estas bases es expresión de su inviabilidad en esos momentos. No obstante, premisas fundamentales no dejarán de estar presentes constantemente a lo largo de nuestra historia.

A medida que se precipitaba la crisis española, crecía el número de los preocupados por la suerte de las colonias. La intención de conformar estados nacionales, mediante la liquidación de las formas precapitalistas de producción (servidumbre indígena, tributo, esclavitud), se convertía en una necesidad imperiosa, pero difícil de lograr ante la multiplicidad de intereses regionales que surgieron con la lucha misma, de ahí que la vía política que se vislumbraba como la más viable era la centralista y autoritaria.

El liderazgo de los grandes caudillos tenderá a la combinación del autoritarismo con ciertas tareas de corte democrático liberal mínimas. El caso de Bolívar es uno de los más representativos de esta situación. El radicalismo de sus decisiones se da en la medida en que las hubo de imponer a despecho de los intereses de los criollos, aunque por otro lado, era consciente de la necesidad de integrar a la élite nativa alrededor de las fuerzas revolucionarias. De ahí la aparente contradicción entre medidas como la del 2 de junio de 1816, cuando se dirige a los habitantes del río Caribe Carúpano y Cariaco y decreta la abolición de la esclavitud, y la del 6 de julio que declara insuficiente la estrategia de la "guerra a muerte" declarando que "ningún español sufriría la muerte por fuera del campo de batalla". De esta manera, se ampliaba la base social de los ejércitos independentistas.

Las perspectivas sociales de los proyectos generados en la revolución de independencia, aun los impulsados por los grandes caudillos, tuvieron el límite preciso de condiciones estructurales que negaban toda posibilidad de cambio a la sociedad. Así por ejemplo, el proyecto bolivariano como opción que reformaba las bases para el planteamiento de la unidad nacional, encontrará enconados opositores en las diversas regiones en donde se trataba de impulsar las tareas mínimas para la restructuración social en función del modelo burgués capitalista.

En el caso de la sociedad altoperuana cuyo carácter conservador hizo que las tareas instrumentadas en la zona por Bolívar y Sucre se vinieran abajo, sobre todo aquellas que se referían a tributación y propiedad territorial indigena. El mayorazgo y la servidumbre gratuita de los indios fueron restablecidos poco después.de que ellos salieron del territorio de la recién conformada nación.

Lo mismo sucedió en Chile con las medidas tomadas por O'Higgins: desde su intento de abolir el mayorazgo en 1818; de eliminar la formación de un capital corporativo en manos de la Iglesia, acumulado sobre la base de "censos" y préstamos a intereses; hasta la abolición del tributo indígena y la esclavitud. De hecho, la caida de O'Higgins se da en la medida en que va afectando intereses seculares, poderosos y firmemente asentados en la conciencia social dominante.

O'Higgins, Bolivar y Sucre entendieron la necesidad de liquidar las 
relaciones de producción y formas de propiedad precapitalista, y en este punto coincidían con los más connotados representanies del radicalismo agrario. Sin embargo. su postura resultó insuficiente frente al poder de los grupos conservadores. por lo cual, sus proyectos tendieron a convertirse en una lucha continua a todo lo largo del siglo xIX.

Realizada la independencia de España, el liberalismo decimonónico se empeñó en liquidar las relaciones precapitalistas de producción y el aparato de Estado colonial. Esto no se logró muy parcialmente, a través del "crecimiento hacia afuera", es decir, de la existencia en la dependencia.

Por todo eso, el liberalismo fue cuestionado - como praxis política y como doctrina filosófica - a la luz de las consecuencias que de su adopción se derivaban. En las tres o cuatro décadas que siguieron a los movimientos revolucionarios de 1810 , se produjeron en todos los países movimientos de polarización antiliberal.

El liberalismo más radical, que sostenía principios de igualdad, fue criticado duramente por el punto de vista ultramontano nutrido del espíritu de la restauración. También fue combatido desde el punto de vista conservador que condenaba la concepción revolucionaria y que sólo admitía un proceso de cambio que fuera lento y evolutivo; pero fue combatido inclusive por un liberalismo moderado que, sin declinar la defensa de los grandes principios, consideraba peligroso aplicarlos sin ajustarlos cuidadosamente a las circunstancias reales de cada sociedad.

El liberalismo latinoamericano fue la expresión de los diversos sectores sociales que sustituyeron a una burguesía industrial inexistente, y que, sin embargo, estaban empeñados en realizar la revolución democrático-burguesa. La derrota de este proyecto ocurre a causa de su dirección pequeñoburguesa. Ello sucede cuando al impulsar ésta las tareas de secularización de la sociedad, la burguesía comercial y el sector agrominero subordinan sus intereses a los del imperialismo norteamericano emergente.

Secularizar la sociedad, era la tarea en que estuvo empeñado el liberalismo a lo largo del siglo xix. Al igual que en México, el movimiento lidereado por Francisco Morazán en Centroamérica perseguía la realización de reformas dirigidas a la desamortización de los bienes del clero, la abolición de los diezmos, democratización de la enseñanza, libertad de cultos, expedición de la ley del divorcio, cambios al poder judicial, transformación de conventos en escuelas, etc. Este proceso reformista, no logrado en su primera etapa de los años 30 , tendió a imponerse en los diversos países con más o menos prontitud en función no sólo del triunfo de los grupos liberales sobre los conservadores, sino de la necesidad de modernizar la sociedad, sobre todo en su expresión urbana, indispensable para asumir nuevos papeles que el proceso de expansión capitalista imponía a las nuevas naciones.

Cuando comienza la etapa de la organización nacional, el federalismo se manifiesta como la opción más radical contra el centralismo político corporativista que, en Hispanoamérica, dejaba intacta la desarticulación económica afirmada sobre una sociedad de terratenientes, servidumbre, tierras vinculadas y a mortizadas, aduanas internas, alcabalas, linajes familiares, etcétera.

El federalismo (a despecho de las intenciones de los grandes caudillos que, generalmente, fueron centralistas) suponía la posibilidad de la organización nacional desde abajo, a partir del desarrollo urbano, la 
eliminación de aduanas internas y de la constitución local de poderes civiles aliados de un poder central en contra de los privilegios corporativos.

Argentina es quizá el único caso donde encontramos que los liberales pugnaron por un Estado unitario (centralista), en tanto que los sectores sociales de filiación precapitalista enarbolan una ideología intransigentemente federalista, de corte caudillesco.

Es a partir de esta contradicción, que surge en esta región la famosa tesis de civilización y barbarie de un Sarmiento en la cual se ve, como única alternativa para lograr la consolidación nacional, la lucha contra lo rural y sus formas de expresión caudillescas y que él aplica desarrollando la ciudad de Buenos Aires, favorecida por el comercio con Inglaterra y Francia; o la tesis europeísta de un Alberdi que ve en la promoción de la inmigración y colonización de las desiertas tierras americanas por europeos que puedan "blanquear" la población, la alternativa de civilizar estas regiones. Así, desde el punto de vista de esta generación, las luchas políticas se inscribian en las luchas por la civilización y contra la barbarie; pero se inscribian, sobre todo, en la lucha contra el autoritarismo, la ignorancia, el dogmatismo. Según ellos, el viejo autoritarismo colonial había sido heredado por caudillos y dictadores surgidos de las guerras civiles que siguieron en casi todos los paises a la independencia. Para ellos, la herencia colonial había que combatirla con inmigración y educación.

El interés por encontrar una explicación a las guerras civiles posindependentistas y a la imposibilidad de conformar los nuevos estados, abrió un debate por la interpretación del pasado nacional que llevó al liberalismo a un enfrentamiento continuo con las posturas ultramontanas a través del periodismo y a desarrollar así una labor historiográfica de gran valor.

Obras como la de Domingo Faustino Sarmiento, Facundo, civilización o barbarie; Sociabilidad chilena de Francisco Bilbao; las biografías realizadas por Bartolomé Mitre de San Martín y Belgrano o las de Benjamín Vicuña Mackenna sobre O'Higgins y Portales; así como la obra de José María Luis Mora, México y sus revoluciones entre tantas otras, forman parte de este interesante debate que debía dar una explicación al surgimiento de las nuevas naciones. Desde esta perspectiva historiográfica, el liberalismo fue cuestionado por el punto de vista conservador, que asumió la defensa del orden colonial con todo lo que él entrañaba.

La crítica al liberalismo desarrollada en esta época, se basó en el análisis de los frutos de la acción política que había inspirado y, sobre todo, en los resultados que había tenido la aplicación de sus principios. Los tradicionalistas y muchos que se seguían diciendo liberales achacaron a esa doctrina la anarquía, el desorden, el empobrecimiento general, la decadencia de las ciudades.

De esta polémica surgió una postura muy particular, la de la necesidad de una dictadura liberal cuya contradicción íntima parecía justificada por la necesidad de que la aplicación de los principios liberales fuera regulada por un poder fuerte, dictatorial ni fuera necesario, para impedir de nueva cuenta el deslizamiento hacia situaciones anárquicas.

A partir del último tercio del siglo xix aproximadamente, se advirtió un cambio sensible en algunas posiciones ideológicas y políticas en diversos países latinoamericanos, el cuestionamiento y la defensa del liberalismo adquirieron otros matices. 
En ese periodo, la penetración de obras fundamentales del positivismo y del cientificismo, especialmente las de Comte, Spencer y Mill a las que se agregaron las de numerosos divulgadores, crearon en el grupo dominante una atmósfera ilustrada y abiertamente pronaturalista y procientificista; aunque por otro lado, las experiencias revolucionarias de 1848 , como las experiencias de restauración monárquica en el Segundo Imperio francés o el sostenido equilibrio de la Inglaterra victoriana, planteaba un nuevo panorama en la consideración del liberalismo que se hallaba cada vez más cercano a las tesis conservadoras.

La posición del liberalismo se había robustecido: Inspiraba el sistema institucional en la mayoría de los países, aunque en los hechos contrariaba la doctrina política liberal del Estado no interventor; complementado con el positivismo y el cientificismo, asumía la postura filosófica predominante, y como dice José Luis Romero, se ofrecía como la fuente más o menos reconocida de las opiniones generalizadas sobre el sentido de la vida, la moral y al convivencia, es decir, los principios del liberalismo, como el individualismo, el racionalismo, la confianza en la legalidad, en la educación, en la transformación evolutiva, se convirtieron en verdades comunes y de sentido común. El progreso y la confianza en la modernidad, inseparables de una concepción liberal de la vida de los sectores urbanos europeizados u occidentalizados, implicaba la aceptación tácita del papel económico impuesto a nuestros paises, y esto era garantía del mantenimiento, en términos generales, del liberalismo económico que, curiosamente, impedía acometer un proyecto de industrialización, garantía a su vez de ese progreso y esa modernización tan ansiada por nuestros liberales y sólo lograda parcialmente en algunas de las grandes ciudades de América Latina.

De hecho, los promotores de estas actitudes fueron las poderosas burguesías agromineras exportadoras e importadoras que se constituyen entonces al calor de la riquéza que trajo a Latinoamérica su inclusión en la periferia de los países industrializados. Con el liberalismo económico lograban consolidar su poderío basado en la producción agrícola y minera para la exportación; y con las nuevs opciones políticas autoritarias lograban el dominio del aparato del Estado y el control de la sociedad.

Una vez que se realiza una organización estatal nacional relativa, mediante una mezcla sui géneris de liberalismo económico, secularización de la sociedad, conservadurismo y centralismo político, el liberalismo siguió siendo objeto de numerosas críticas tanto de los que trataban de recuperar sus premisas fundamentales de democratización de la sociedad como de los que lo veían como una suerte de radicalismo impracticable. Por su parte, los socialistas comenzaron a hacer también sus propias críticas a partir de posturas nuevas y reivindicando la participación de sectores sociales emergentes, como los trabajadores urbanos, mineros o del campo.

El liberalismo es un proyecto humanista e industrial burgués. Dado que la burguesía prácticamente no existia en Latinoamérica, fue aplicado sólo en ciertos aspectos por las oligarquías latinoamericanas, de tal manera que algunos de los principios liberales, de hecho, seguirían presentes hasta nuestros días, como tareas necesarias a realizar para lograr la formación de un Estado nacional democrático-burgués. El panorama era complicado, porque no sólo se establecían limitaciones en las relaciones de producción, que eran mantenidas generalmente en 
los niveles feudales (servidumbre, esclavitud), sino también por las que impuso el imperialismo y que contribuyeron, en la mayoria de nuestros paises a que no se formaran burguesías nacionales capaces de realizar dicha tarea.

En conclusión, podemos decir que algunas de las reformas propuestas por el liberalismo tendieron a realizarse en América Latina, no por una burguesía industrial que, aquí era prácticamente inexistente, sino por una oligarquia que se apropió en su beneficio de esta labor después de derrotar a todos aquellos sectores que podian radicalizarse tomando en un sentido más amplio algunas de las tesis del liberalismo (como había sucedido con algunos proyectos en la etapa de la revolución de independencia).

Aspectos que para la oligarquía terrateniente de las tres primeras décadas del siglo no podían ni mencionarse, como la supresión de las cargas impositivas sobre la fuerza de trabajo indigena, hacia 1860 ó 1870 ella misma los enarbolaba como bandera por su afán de situarse dentro de la nueva perspectiva del capitalismo. La demanda de nuevos productos por el mercado mundial abría muchas posibilidades a esta oligarquía antes temerosa de perder una de sus fuentes de riqueza.

La liberalización del comercio se había ido asentando en la medida en que se fueron encontrando productos que pudieron equilibrar la balanza de pagos de una sociedad y una economía coloniales.

La liberalización de la fuerza de trabajo fue la tarea que más trabajo costó y sólo se dio de una manera muy lenta, aun en aquellas zonas donde la presión imperialista era fuerte. Actuaron en favor de dicha tendencia, la necesidad de promover la racionalidad en la utilización de la fuerza de trabajo y el ahorro que implicaba dejar en las propias manos del trabajador su reproducción.

En términos políticos, el liberalismo suponía la creación de un aparato de estado humanista, pero en el realizado por la oligarquía ésta ejercía un poder generalmente extralimitado que contradecía los principios fundamentales del liberalismo, y que, por la estructura económica de América Latina, se hacía parecer inevitable.

Sus logros, contradictorios si se quiere, fueron la relativa unidad nacional, la secularización del Estado, la relativa estabilidad impuesta por una oligarquía que había logrado la reapropiación de la gran propiedad agrícola y que, por lo tanto, había impedido la aplicación de uno de los ideales del liberalismo pequeñoburgués, el de la formación de la pequeña y mediana propiedad que llevaría a la realización de la utopía roussoniana de la república de propietarios. Más bien, si exceptuamos algunos casos, como el de Costa Rica, podriamos hablar de una república de grandes propietarios donde la mayor parte de la población quedaría al margen de cualquier posibilidad de serlo.

En términos sociales se crearon numerosas contradicciones dado que la estructura económica (gran propiedad agraria, poca elasticidad social, nexos dependientes con los imperios) imposibilitaba el camino hacia la partucipación democrática, no obstante que, el crecimiento de los sectores medios en las urbes, el desarrollo de grupos de trabajadores en el campo y la ciudad hacia finales del siglo xix la hacian necesaria. Así, ciertas opciones que el liberalismo de la oligarquía no podía realizar por afectar a su propia posibilidad de existir, ya que ella misma exa un remanente del régimen colonial tendieron a asumirlos los grupos emergentes en el fin del siglo y bajo nuevas perspectivas. La participación democrática era una de estas opciones. Hoy nos preguntamos, el siglo xx ¿la ha logrado?... 